\title{
The Kinetics of B-a and P-a Type Copolybenzoxazine via the Ring Opening Process
}

\author{
Yi-Che Su, Ding-Ru Yei, Feng-Chih Chang \\ Institute of Applied Chemistry, National Chiao-Tung University, Hsin-Chu, Taiwan
}

Received 15 May 2003; accepted 23 July 2004

DOI 10.1002/app.21244

Published online in Wiley InterScience (www.interscience.wiley.com).

\begin{abstract}
The structure of benzoxazines is similar to that of phenolic resin through thermal self-curing of the heterocyclic ring opening reaction that neither requires catalyst nor releases any condensation byproduct. These polybenzoxazine resins have several outstanding properties such as high thermal stability and high glass transition temperature. To better understand the curing kinetics of this copolybenzoxazine thermosetting resin, dynamic and isothermal differential scanning calorimetry measurements were performed. Three models, the Kissinger method, the FlynnWall-Osawa method, and the Kamal method, were used to
\end{abstract}

describe the curing process. Dynamic kinetic activation energies based on Kissinger and Flynn-Wall-Osawa methods are 72.11 and $84.06 \mathrm{KJ} / \mathrm{mol}$, respectively. The Kamal method based on an autocatalytic model results in a total order of reaction between 2.66 and 3.03, depending on curing temperature. Its activation energy and Arrhenius preexponential are $50.3 \mathrm{KJ} / \mathrm{mol}$ and 7959, respectively. (C) 2004 Wiley Periodicals, Inc. J Appl Polym Sci 95: 730-737, 2005

Key words: benzoxazine; heterocyclic; ring opening; kinetics; activation energy

\section{INTRODUCTION}

The benzoxazine oligomeric products and polybenzoxazine (PBZZ) resins were investigated recently., The benzoxazine can be cured via a thermal ring opening reaction to construct an analogous phenolic structure characterized by a Mannich base bridge $\left(-\mathrm{CH}_{2}-\right.$ NR- $\left.-\mathrm{CH}_{2}\right) \cdot{ }^{3}$ Furthermore, the preferred reaction site is the position ortho to the hydroxyl functionality on the aromatic ring. In addition, these PBZZ resins possess several outstanding properties such as near-zero shrinkage after curing, ${ }^{4}$ low water absorption, ${ }^{5}$ and high thermal stability. Furthermore, the PBZZ has a higher glass transition temperature even thought it has relatively low cross-linking density. ${ }^{6}$

PBZZ can be formed by the heterocyclic curing via the ring opening process. Hence, controlling the curing conditions of the thermal curing process, such as temperature and time, will result in a notable difference in thermal properties. In this study, we selected B-a type and P-a type benzoxazines to form random co-PBZZ as shown in Scheme 1. The degree of crosslinking depends upon the ratio of B-a/P-a benzoxazine, curing temperature, and time. The kinetics of polymerization was investigated using differential scanning calorimetry (DSC) and Fourier transform in-

Correspondence to: F.-C. Chang (changfc@cc.nctu.edu.tw).

Journal of Applied Polymer Science, Vol. 95, 730-737 (2005)

(C) 2004 Wiley Periodicals, Inc. frared (FT-IR) spectroscopy during isothermal and dynamic curing processes in this study.

\section{EXPERIMENTAL}

\section{Materials}

The B-a type benzoxazine based on bisphenol-A, formaldehyde, and aniline and the P-a type based on phenol, formaldehyde, and aniline were synthesized as shown in Scheme 2. ${ }^{7}$ Both bisphenol-A and phenol were purchased from Showa Chemical Co. of Japan. Formaldehyde and aniline were purchased from Aldrich Chemical Co.

\section{Reactants preparations}

A blend of B-a type and P-a type co-PBZZ with equal molar composition was prepared by solution blending. The monomer mixture was stirred and dissolved in acetone. The solution was allowed to evaporate slowly at $50^{\circ} \mathrm{C}$ under vacuum for 1 day and the sample was used for isothermal and dynamic curing experiments. Afterward, the sample was further postcured at different curing temperatures for $4 \mathrm{~h}$ under vacuum to ensure total curing of the co-PBZZ.

\section{Differential scanning calorimetry}

Calorimetric measurements were performed using a TA Instruments differential scanning calorimeter (DSC-2010). Both isothermal and dynamic-heating ex- 


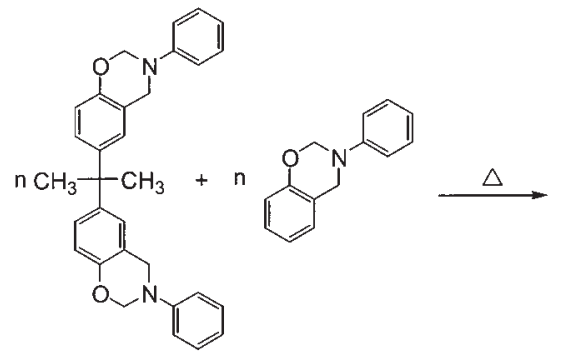

benzoxazine ( $\mathrm{B}-\mathrm{a}$ type) benzoxazine ( $\mathrm{P}$-a type)

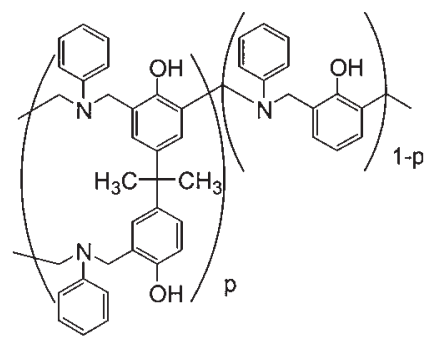

random co-PBZZ

Scheme 1

periments were conducted under a nitrogen flow of 25 $\mathrm{mL} / \mathrm{min}$.

\section{Isothermal curing}

The sample (equal molar ratio of B-a and P-a type benzoxazine) was placed in the $\mathrm{Al}$ cell at room temperature and the temperature was then raised quickly to a preset temperature for each isothermal experimental. The instrument will achieve stability about $60 \mathrm{~s}$ after reaching the setting temperature and data will be recorded immediately. When the DSC exothermic peak reaches the baseline level, the isothermal curing process is complete and the heat of reaction can be measured by integrating the exothermic peak area. Thereafter, the sample is cooled to $30^{\circ} \mathrm{C}$ and reheated from 30 to $300^{\circ} \mathrm{C}$ at a rate of $10^{\circ} \mathrm{C} / \mathrm{min}$ to determine the residual heat of the unreacted portion. These isothermal curing curves can be used to evaluate kinetic parameters of the curing reaction.

\section{Dynamic curing}

A nonisothermal experiment was carried out at 1, 5,10, or $20^{\circ} \mathrm{C} / \mathrm{min}$ from 30 to $300^{\circ} \mathrm{C}$ and integrated the area of exothermic peak. We assume that the total recorded heat of reaction represents the total heat evolved from complete curing at different curing rates.

\section{Glass transition temperatures measurement}

The samples was cured at $160,180,190,200$, or $210^{\circ} \mathrm{C}$ for $4 \mathrm{~h}$ in an oven to ensure total curing of the coPBZZ. Then, all samples were preheated with a scan rate of $20^{\circ} \mathrm{C} / \mathrm{min}$ from 30 to $260^{\circ} \mathrm{C}$ and maintained at $260^{\circ} \mathrm{C}$ for $2 \mathrm{~min}$. The measurement was made using a 5- to 10-mg sample on a DSC sample pan after the cell was quickly cooled to $30^{\circ} \mathrm{C}$ from the melt of the first scan. The second scan rate was $20^{\circ} \mathrm{C} / \mathrm{min}$ from 30 to $300^{\circ} \mathrm{C}$ and $T_{\mathrm{g}}$ was taken as the midpoint of the heat capacity transition between the upper and lower points of deviation from the extrapolated liquids and glass lines.

\section{Infrared spectroscopy}

FT-IR measurement was recorded on a Nicolet Avatar 320 FT-IR spectrophotometer. A total of 32 scans were collected with a spectral resolution of $1 \mathrm{~cm}^{-1}$. Infrared (a)

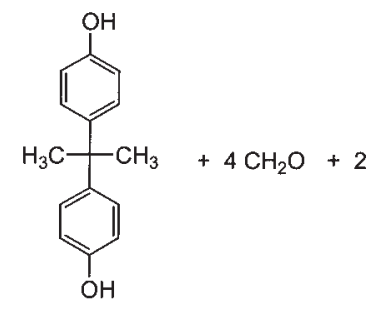

(b)

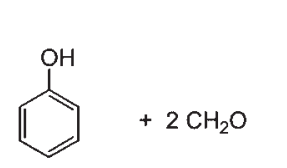

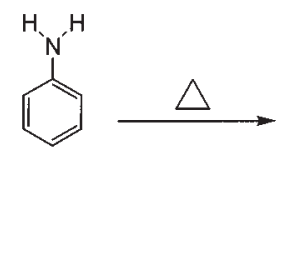

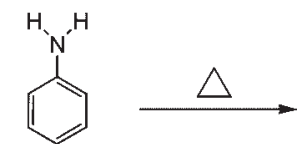<smiles>CC(C)(c1ccc2c(c1)CN(c1ccccc1)CO2)c1ccc2c(c1)CN(c1ccccc1)CO2</smiles><smiles>c1ccc(N2COc3ccccc3C2)cc1</smiles>

Scheme 2 


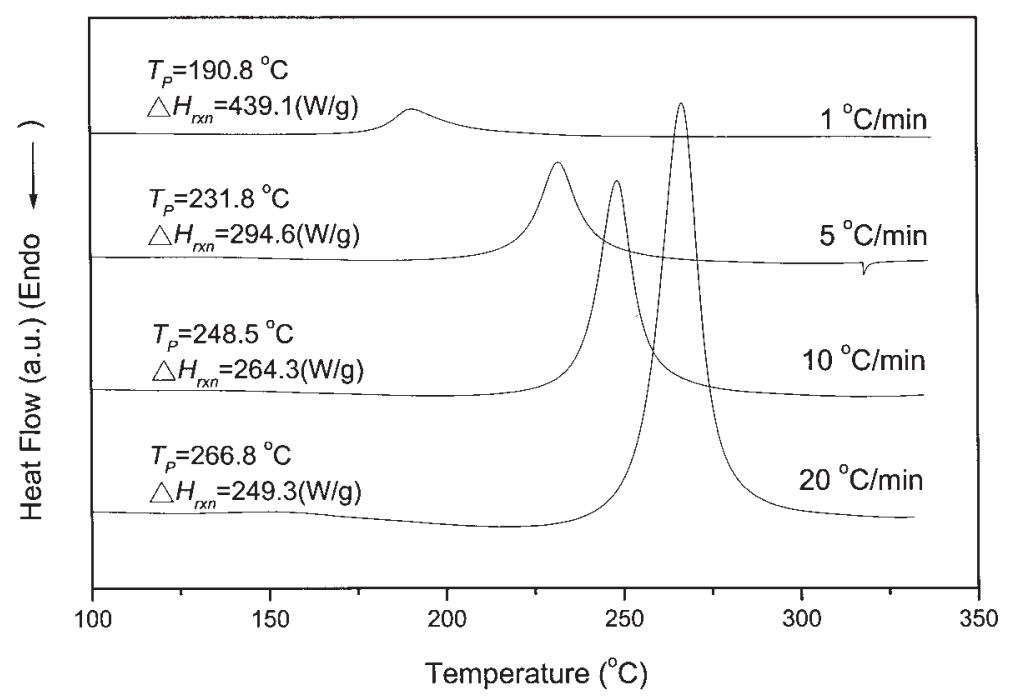

Figure 1 Dynamic DSC exothermic curves at different scan rates.

spectra of the copolymers were obtained using the conventional $\mathrm{KBr}$ method. The film used in this study was thin enough to obey the Beer-Lambert law. The sample chamber was purged with nitrogen during process of measurement to maintain the sample film drying.

\section{RESULTS AND DISCUSSION}

\section{Scanning DSC studies}

Figure 1 shows the DSC exothermic peaks from different dynamic heating rates ${ }^{8,9}$ at $1,5,10$, and $20^{\circ} \mathrm{C} /$ min, respectively. A faster heating rate results in a higher maximum temperature $\left(T_{p}\right)$ since the sample has a shorter time to react and to release the heat of reaction. In addition, lower the heating rate results in larger exothermic heat per unit weight, as expected, and results are summarized in Figure 1. The amount of exothermic heat from the slowest heating rate at $1^{\circ} \mathrm{C} / \mathrm{min}$ can be considered the total heat released to completely cure the sample and the total heat $\left(\triangle H_{\mathrm{rxn}}\right)$ is obtained is $439.1(\mathrm{~W} / \mathrm{g})$. The $(d H / d t)_{\text {iso }}$ can be calculated from the trace of the isothermal DSC curve. The reaction rate $(d \alpha / d t)$ at a preset curing temperature can be obtained by Eq. (1):

$$
\frac{d \alpha}{d t}=\frac{(d H / d t)_{\text {iso }}}{\Delta H_{\mathrm{rxn}}} .
$$

Figure 2 shows the reaction rates of co-PBZZ as a function of curing time for different curing temperatures. All samples were cured without the addition of any catalyst, and only a single exothermic peak was observed in all DSC curves. In other words, this heterocyclic ring opening curing reaction simply involves a single exothermic chemical process. As expected, at a higher curing temperature the curing rate $(d \alpha / d t)$ is higher and the curing time period is shorter. Figure 3 illustrates conversion $(\alpha)$ versus isothermal curing time at various curing temperatures. When the curing temperature rises from 160 to $220^{\circ} \mathrm{C}$, the conversion increases ${ }^{10}$ from 0.35 to 0.93 . Figure 4 shows plots of reaction rate versus conversion for different curing temperatures. The maximum reaction rate occurs between $20\left(180^{\circ} \mathrm{C}\right)$ and $38 \%\left(220^{\circ} \mathrm{C}\right)$ of conversion. This

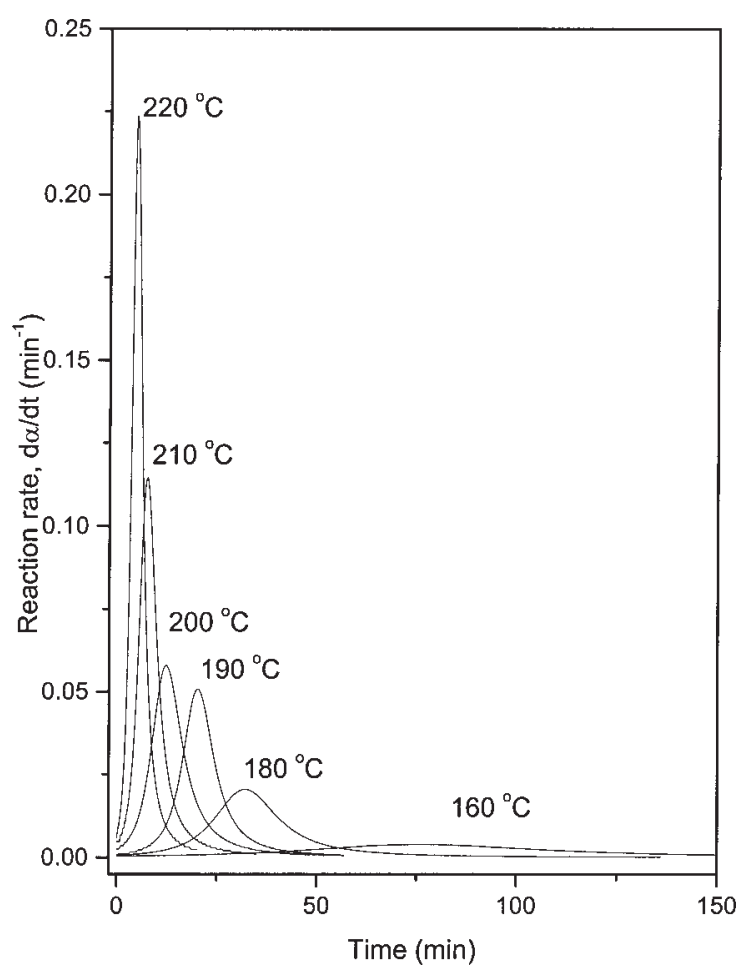

Figure 2 Reaction rate versus isothermal curing time at different curing temperatures. 


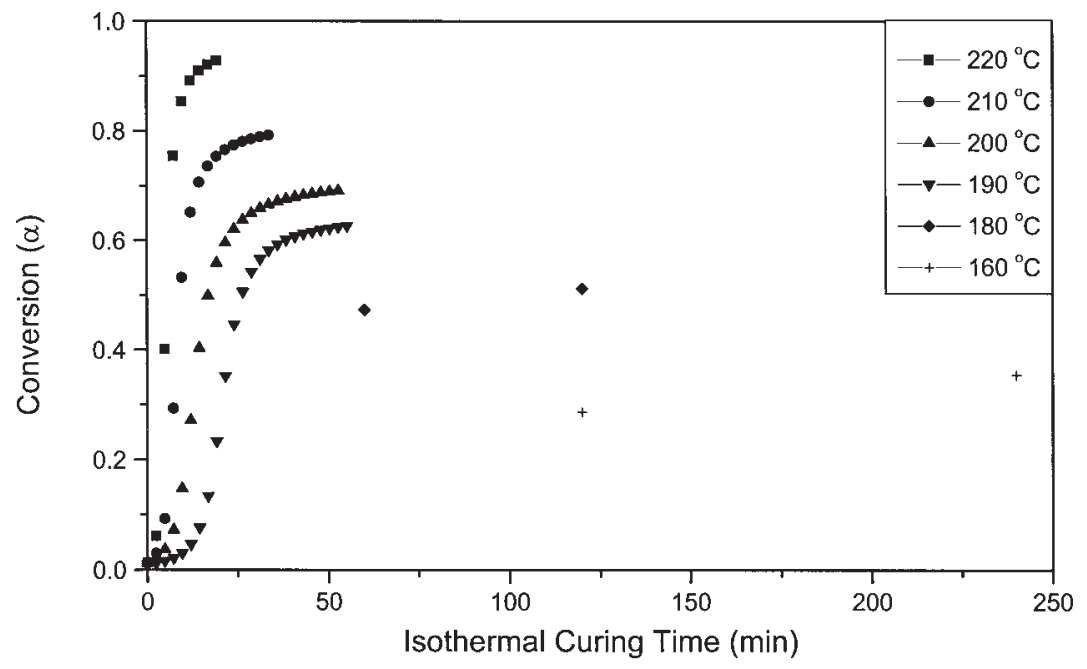

Figure 3 Conversion versus isothermal curing time at different curing temperatures.

result confirms that the curing process follows an autocatalytic model with maximum reaction rate between 20 and $40 \%$ conversion. $^{11}$

\section{Kinetic analysis}

Kinetic analysis can be performed mostly using three kinetic models: ${ }^{12}$ the Kissinger ${ }^{13}$ and Flynn-Wall-Osawa ${ }^{14}$ methods are suitable for dynamic kinetic anal-

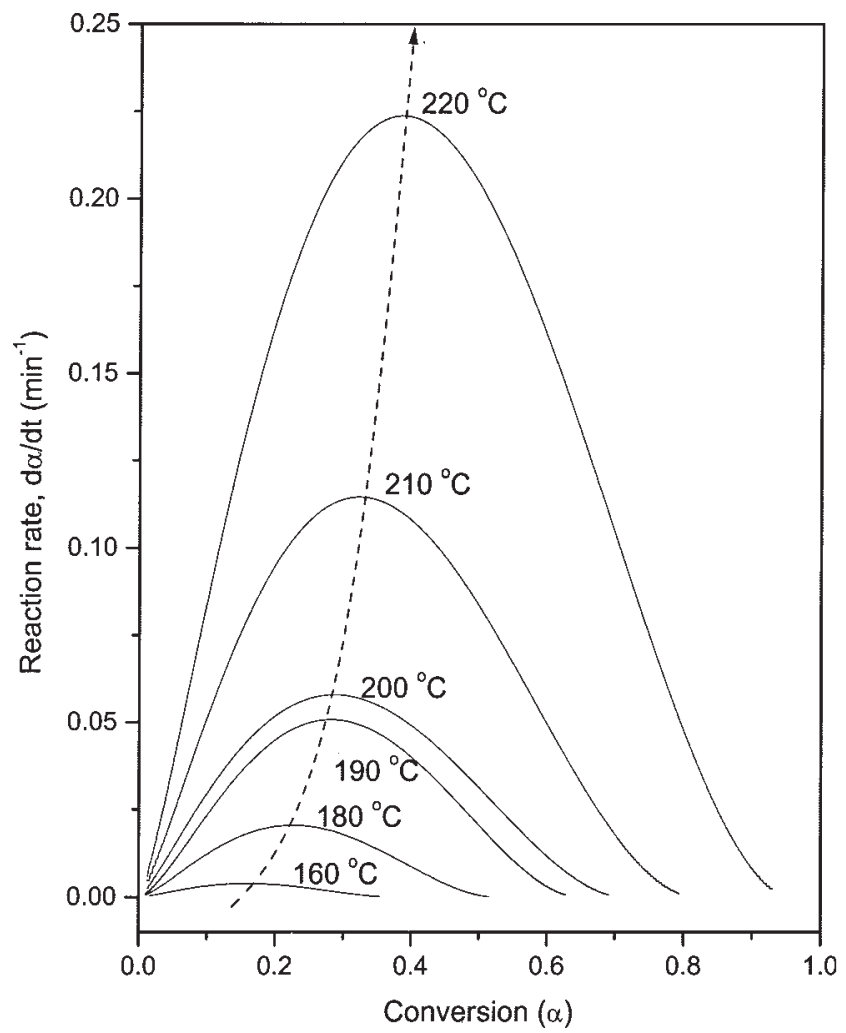

Figure 4 The tendency of reaction rate versus conversion. ysis, while the Kamal method ${ }^{15}$ is suitable for isothermal kinetic analysis (autocatalytic model).

The extent of reaction, $\alpha$, is proportional to the heat generated during the reaction. The reaction rate is a function of conversion, which can be expressed by the general law as shown in Eq. (2),

$$
\frac{d \alpha}{d t}=k(T) f(\alpha)
$$

where $t$ is the time, $k(T)$ is the rate constant, and $f(\alpha)$ is a function of dependence of conversion. By integrating the above equation, a new equation can be obtained as follows:

$$
g(\alpha)=\int_{0}^{\alpha} \frac{d \alpha}{f(\alpha)}=k(T) t
$$

where $g(\alpha)$ is the integrated form of the conversiondependent function.

\section{Dynamic kinetic method}

Nonisothermal analysis can include the single heating rate method and the multiple heating rate method. The single heating method measures the curing process based on only a single constant rate cycle suitable for the $n$ th-order reaction. Furthermore, these multiple heating rate methods are applicable for both $n$ th-order and autocatalytic reactions. Two such multiple heating rate methods were proposed by Kissinger ${ }^{13}$ and Flynn-Wall-Ozawa. ${ }^{14}$ These two methods were used in this study instead of other nonisothermal methods 


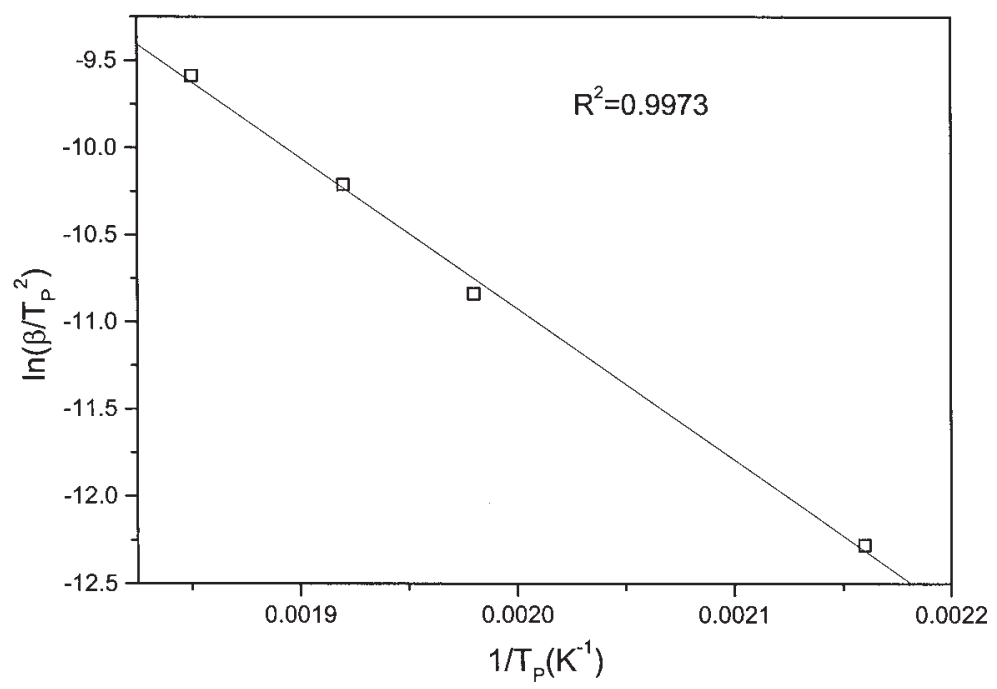

Figure 5 Plots for determination of the activation energy of curing reaction by the Kissinger method.

because they do not require prior knowledge of the reaction mechanism to quantify kinetic parameters.

(a) The Kissinger method

Based on the Kissinger method, the activation energy can be obtained while the maximum reaction rate

$$
\frac{d(d \alpha / d t)}{d t}
$$

is zero under a constant heating rate condition. The resulting relation can be expressed by Eq. (4)

$$
\ln \left(\frac{\beta}{T_{\mathrm{p}}^{2}}\right)=\ln \left(\frac{A R}{E_{\mathrm{a}}}\right)-\frac{E_{\mathrm{a}}}{R T_{\mathrm{p}}}
$$

where $\beta=d T / d t$ is a constant heating rate, $T_{\mathrm{p}}$ is the maximum exothermic temperature, and $R$ is the universal gas constant. By plotting

$$
\ln \left(\frac{\beta}{T_{\mathrm{p}}^{2}}\right)
$$

versus

$$
\frac{1}{T_{\mathrm{p}}}
$$

which gives the activation energy without a specific assumption of the conversion-dependent function, we calculated the slope as shown in Figure 5.

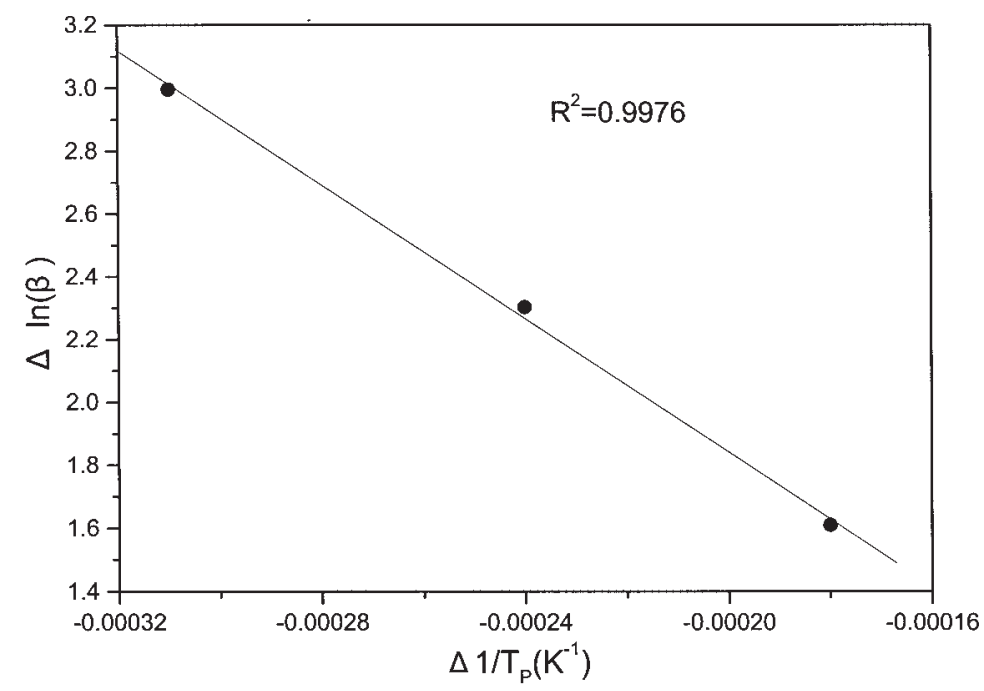

Figure 6 Plots for determination of the activation energy of curing reaction by the Flynn-Wall-Ozawa method. 
Therefore, the value of $E_{\mathrm{a}}$ of $72.11 \mathrm{KJ} / \mathrm{mol}$ was obtained.

\section{(b) Flynn-Wall-Ozawa method}

The Flynn-Wall-Ozawa method is another widespread method used to describe the dynamic kinetic analysis without any assumptions on the conversiondependence function. Its general expression can be represented by Eq. (5).

$$
E_{\mathrm{a}}=\frac{-R}{1.052} \frac{\Delta \ln \beta}{\Delta\left(1 / T_{\mathrm{p}}\right)}
$$

By plotting $\Delta \ln \beta$ versus $\Delta\left(1 / T_{\mathrm{P}}\right)$ we can obtain the slope value equal to

$$
\frac{\Delta \ln \beta}{\Delta\left(1 / T_{\mathrm{p}}\right)}
$$

by the least-squares technique to improve the linear approximation on the temperature integration term at Figure 6. Thus, the activation energy of $E_{\mathrm{a}}=84.06$ $\mathrm{KJ} / \mathrm{mol}$ was obtained.

\section{Isothermal kinetic analysis (autocatalytic model)}

The autocatalytic model is a phenomenological approach developed by Kamal. Since the system is autocatalytic, the reaction rate can be described by the following general expression for autocatalyzed systems:

$$
\frac{d \alpha}{d t}=k \alpha^{m}(1-\alpha)^{n},
$$

where $\alpha$ is the reaction conversion, $k$ is the kinetic rate constant, $m$ and $n$ are the kinetic exponents of the reaction, and $m+n$ is the overall reaction order.

However, in practice, the curing reaction will cease when the reaction conversion reaches the maximum value $\left(\alpha_{\max }\right)$. Then, Eq. (6) must be corrected and changed into Eq. (7). ${ }^{16-18}$

$$
\begin{gathered}
\frac{d \alpha}{d t}=k \alpha^{m}\left(\alpha_{\max }-\alpha\right)^{n} \\
\left(\text { when } \alpha=\alpha_{\max } \Rightarrow \frac{d \alpha}{d t}=0\right),
\end{gathered}
$$

where $\alpha_{\max }$ is based on different curing temperatures. To rearrange and take the nature logarithm of Eq. (7), Eqs. (8) and (9) are obtained. We use the iteration method to calculate the approximate values of $m, n$, and $k$ according to Eqs. (8) and (9). When $n_{i+1}-n_{i}$ $<0.01$, the iteration will be stopped. Then, the values
TABLE I

The Values of $m, n$, and $k$ and Total Order of Different Curing Temperature

\begin{tabular}{ccccc}
\hline $\begin{array}{c}\text { Curing temp. } \\
\left({ }^{\circ} \mathrm{C}\right)\end{array}$ & $m$ & $n$ & $k(1 / \mathrm{min})$ & $m+n$ \\
\hline 220 & 1.36 & 1.67 & 2.19 & 3.03 \\
210 & 1.26 & 1.70 & 1.70 & 2.96 \\
200 & 1.35 & 1.55 & 1.25 & 2.90 \\
190 & 1.27 & 1.46 & 1.18 & 2.73 \\
180 & 1.15 & 1.52 & 0.75 & 2.67 \\
160 & 1.23 & 1.43 & 0.39 & 2.66 \\
\hline
\end{tabular}

of $m, n$, and $k$ of different curing temperatures are obtained. The results are listed in Table I.

$$
\begin{gathered}
\ln \left(\frac{(d \alpha / d t)}{\left(\alpha_{\max }-\alpha\right)^{n}}\right)=\ln k+m \ln \alpha \\
\ln \left(\frac{(d \alpha / d t)}{k \alpha^{m}}\right)=n \ln \left(\alpha_{\max }-\alpha\right)
\end{gathered}
$$

In additional, the rate constant, $k$, may be described by the Arrhenius expression, ${ }^{16}$

$$
k=A e^{-E_{\mathrm{a}} / R T},
$$

where $A$ is the Arrhenius preexponential factor (or frequency factor), $E_{\mathrm{a}}$ is the energy of activation, $R$ is the universal gas constant, and $T$ is the absolute temperature.

Taking the nature logarithm of Eq. (10), we obtain Eq. (11). We plot $\ln k$ versus $1000 / T$ for different isothermal curing temperatures; data are shown in Figure 7 . The activation energy of $E_{\mathrm{a}}=50.3 \mathrm{KJ} / \mathrm{mol}$ and $\ln A=8.982(\mathrm{~A}=7959)$ is obtained.

$$
\ln k=\ln A-E_{\mathrm{a}} / R T .
$$

Comparing the three kinetic models, the values of the activation energy can be obtained from both dynamic and isothermal analysis. Hence, it is appropriate to calculate the activation energy and kinetic parameters including $m, n$, and $k$ using the Kissinger, Flynn-WallOzawa, and Kamal methods in this system.

\section{Glass transition temperature analysis}

Figure 8 shows traces of DSC thermograms of B-a and $\mathrm{P}$-a type co-PBZZ under various curing temperatures for $4 \mathrm{~h}$. Under all conditions, the polymer blend gives only a single glass transition temperature because of similar structure. In addition, by increasing the curing temperature, the $T_{\mathrm{g}}$ also increases with until $190^{\circ} \mathrm{C}$ or above. Then, the $T_{g}$ will remain at a near-constant value, ${ }^{19}$ which is about $173^{\circ} \mathrm{C}$. In other words, the 


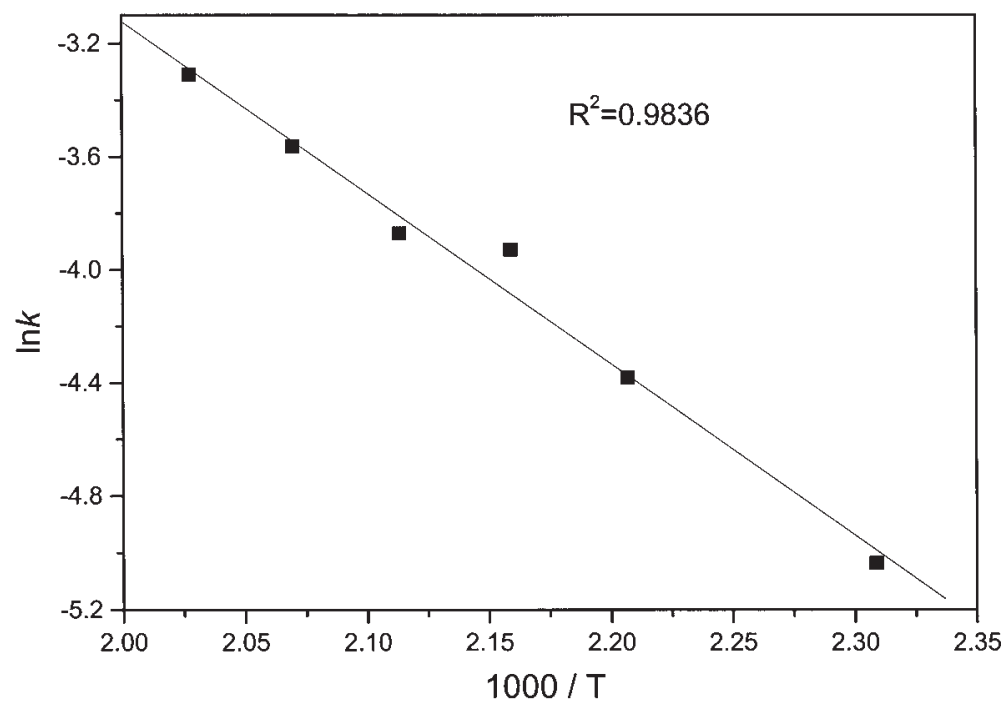

Figure 7 Plots of $\ln k$ versus 1000/T for determination of the activation energy and Arrhenius preexponential of the curing reaction by the isothermal method.

different curing temperatures affect the degree of curing and result in different glass transition temperatures until the maximum $T_{\mathrm{g}}$ is reached at $173^{\circ} \mathrm{C}$.

\section{Fourier transfer infrared spectroscopy analysis}

The FT-IR spectra ${ }^{20,21}$ of B-a type and P-a type benzoxazine copolymers after different temperature treat-

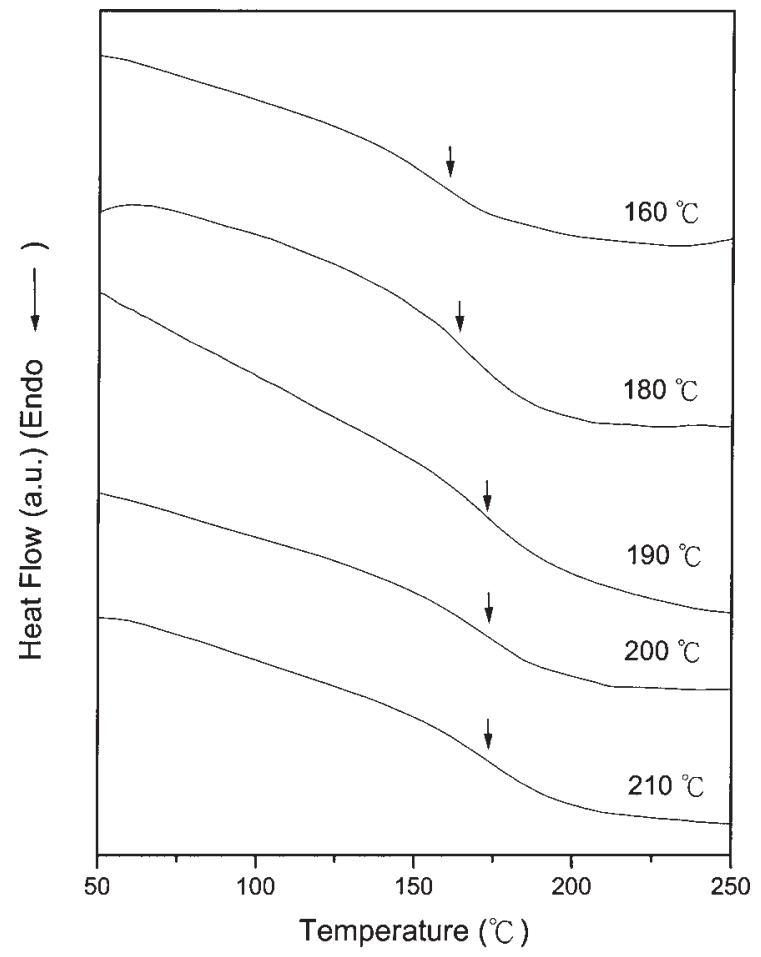

Figure 8 The DSC curves at different curing temperatures for $4 \mathrm{~h}$. ments were recorded and are shown in Figure 9a. The bands of 748 and $691 \mathrm{~cm}^{-1}$, corresponding to the monosubstituted benzene, are still present even after high-temperature curing. On the contrary, the characteristic absorption band of the oxazine ring at 947 $\mathrm{cm}^{-1}$ disappeared, and the absorption at $1495 \mathrm{~cm}^{-1}$ from the trisubstituted benzene ring and at $1236 \mathrm{~cm}^{-1}$ from the $\mathrm{CH}_{2}$ wagging both decreased. However, a new absorption band appeared at $1478 \mathrm{~cm}^{-1}$ due to the tetrasubstituted benzene ring mode. Besides, the absorptions at 1030 and $1230 \mathrm{~cm}^{-1}$ corresponding to the symmetric and asymmetric $\mathrm{C}-\mathrm{O}-\mathrm{C}$ bonds of the benzoxazine, disappear after the curing process. Furthermore, a broad hydroxyl bond is formed because of the ring opening process as shown in Figure 9b. Based

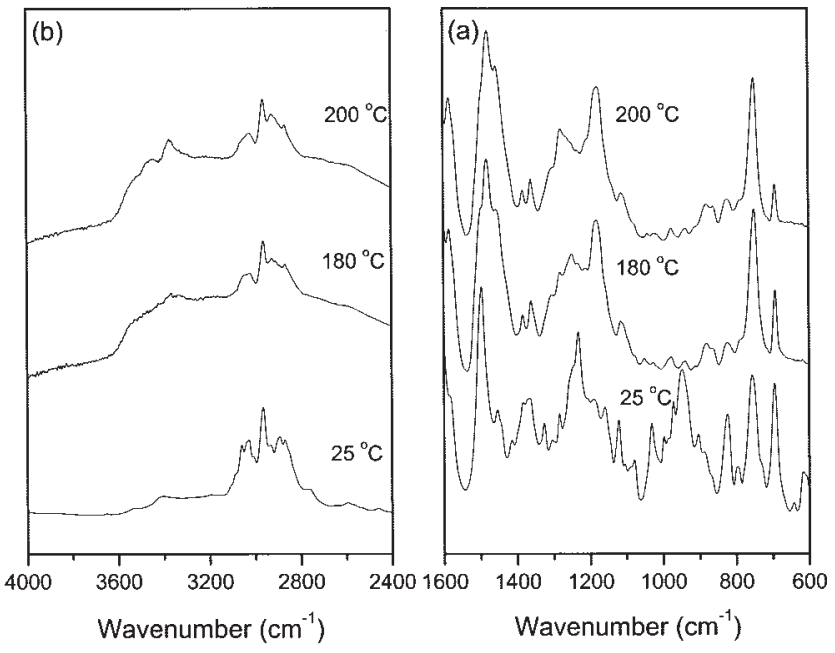

Figure 9 FTIR spectra recorded at room temperature between (a) 600 and $1600 \mathrm{~cm}^{-1}$ and (b) 2400 and $4000 \mathrm{~cm}^{-1}$ 
on DSC and FT-IR results, the ring opening reaction indeed occurs as shown in Scheme 1.

\section{CONCLUSION}

Based on the DSC results, the equal molar mixture of $\mathrm{B}-\mathrm{a}$ type and $\mathrm{P}$-a type co-PBZZ is completely miscible in the amorphous phase and gives a single glass transition temperature. The product $T_{\mathrm{g}}$ depends upon the ratio of $\mathrm{B}-\mathrm{a} / \mathrm{P}-\mathrm{a}$ benzoxazine, curing temperature, and curing time. The maximum $T_{\mathrm{g}}$ is about $173^{\circ} \mathrm{C}$. The isothermal curing process of the co-PBZZ precusor involves an autocatalytic- type curing mechanism. In the dynamic experiments, the activation energy is $72.11 \mathrm{KJ} / \mathrm{mol}$ based on the Kissinger method and $84.06 \mathrm{KJ} / \mathrm{mol}$ based on the Flynn-Wall-Ozawa method. Furthermore, in the isothermal experiments, the activation energy and Arrhenius preexponential are $50.3 \mathrm{KJ} / \mathrm{mol}$ and 7959 based on the Kamal method, and the total order of reaction is between 2.66 and 3.03 , depending on the isothermal curing temperature.

\section{References}

1. Kim, H. J.; Brunovska, Z;. Ishida, H. Polymer 1999, 40, 1815.

2. Kim, H. J.; Brunovska, Z.; Ishida, H. Polymer 1999, 40, 6565.

3. Ishida, H.; Allen, D. J. J Polym Sci Polym Phys 1996, 34, 1019.

4. Ishida, H. J Appl Polym Sci 1995, 58, 1751.

5. Ishida, H.; Low, H. Y. Macromolecules 1997, 30, 1099.

6. Ning, X.; Ishida, H. J Polym Sci Polym Phys 1994, 32, 921.

7. Ning, X.; Ishida, H. Polym Sci Polym Chem 1994, 32, 1121.

8. Zvetkov, V. L. Polymer 2001, 42, 6687.

9. Jost, N.; Koocsis, J. K. Polymer 2002, 43, 1383.

10. Kim, W.G.; Lee, J. Y. Polymer 2002, 43, 5713.

11. Boey, F. Y. C.; Qiang, W. Polymer 2000, 412081.

12. Barral, L.; Cano, J.; Lopez, I.; Bueno, L.; Nogueira, P.; Abad, M. J.; Ramirez, C. J Polym Sci Polym Phys 2000, 38, 351.

13. Kissinger, H. E. Anal Chem 1957, 29, 1702.

14. Ozawa, T.J Therm Anal 1970, 2, 301.

15. Kamal, M. R. Polym Eng Sci 1974, 27, 782.

16. Fischer, M.; Tran, C. D. Anal Chem 1999, 71, 953.

17. Cole, R. C. Macromolecules 1991, 24, 3093.

18. Cole, K. C.; Hechler, J. J.; Nobel, D. Macromolecules 1991, 24, 3098.

19. Shen, S. B.; Ishida, H. J Polym Sci Polym Phys 1999, 37, 3257.

20. Agag, T.; T. Takeichi, T. Macromolecules 2001, 34, 7257.

21. Ishida, H.; Sanders, D. P. Macromolecules 2000, 33, 8149. 